\title{
Article \\ Dynamics of Cardiovascular Muscle Using a Non-Linear Symmetric Oscillator
}

\author{
Soumyendu Bhattacharjee ${ }^{1}$, Aishwarya Banerjee ${ }^{2}$, Amit Rakshit ${ }^{3}$, Swapan Bhattacharyya ${ }^{4}$, Swati Chowdhuri ${ }^{5}$, \\ Biswajit Sarkar ${ }^{6, *(1)}$ and Biswarup Neogi 7 (D)
}

1 Department of Electronics Science, West Bengal State University, Barasat 700126, West Bengal, India; s_vlsi@yahoo.in

2 Electronics and Communication Engineering, Tech-Lateetud Private Limited, Kolkata 700091, India; aishwarya.b1990@gmail.com

3 Department of Mechanical Engineering, Kanad Institute of Engineering \& Management, Mankar 713144, India; kanadinstituteofengg@gmail.com

4 Department of Electronics \& Communication Engineering, Siliguri Institute of Technology, Salbari, P.O., Sukna, Dist., Darjeeling 734009, West Bengal, India; swapanbhattacharyya@ieee.org

5 Institute of Engineering and Management, Salt Lake Electronics Complex, Sector V, Kolkata 700091, West Bengal, India; swati.chowdhuri@gmail.com

6 Department of Industrial Engineering, Yonsei University, 50 Yonsei-ro, Sinchon-dong, Seodaemun-gu, Seoul 03722, Korea

7 Department of Electronics \& Communication Engineering, JIS College of Engineering, Kalyani 741235, India; biswarup.neogi@jiscollege.ac.in

* Correspondence: bsbiswajitsarkar@gmail.com or bsarkar@yonsei.ac.kr

\section{check for}

updates

Citation: Bhattacharjee, S.; Banerjee, A.; Rakshit, A.; Bhattacharyya, S.; Chowdhuri, S.; Sarkar, B.; Neogi, B. Dynamics of Cardiovascular Muscle Using a Non-Linear Symmetric Oscillator. Symmetry 2021, 13, 151. https://doi.org/10.3390/sym13010151

Received: 13 December 2020

Accepted: 11 January 2021

Published: 18 January 2021

Publisher's Note: MDPI stays neutra with regard to jurisdictional claims in published maps and institutional affiliations.

Copyright: (C) 2021 by the authors Licensee MDPI, Basel, Switzerland. This article is an open access article distributed under the terms and conditions of the Creative Commons Attribution (CC BY) license (https:// creativecommons.org/licenses/by/ $4.0 /)$.
Abstract: In this paper, a complete non-linear symmetric oscillator model using the Hamiltonian approach has been developed and used to describe the cardiovascular conduction process's dynamics, as the signal generated from the cardiovascular muscle is non-deterministic and random. Electrocardiogram (ECG) signal is a significant factor in the cardiovascular system as most of the medical diagnoses can be well understood by observing the ECG signal's amplitude. A non-linear cardiovascular muscle model has been proposed in this study, where a modified vanderPol symmetric oscillator-based equation is used. Gone are the days whena non-linear system had been designed using the describing function technique. It is better to design a non-linear model using the Hamiltonian dynamical equation for its high accuracy and flexibility. Varying a non-linear spring constant using this type of approach is more comfortable than the traditional describing function technique. Not only that but different initial conditions can also be taken for experimental purposes. It never affects the overall modeling. The Hamiltonian approach provides the energy of an asymmetric oscillatory system of that cardiovascular conduction system. A non-linear symmetric oscillator was initially depicted by the non-linear mass-spring (two degrees of freedom) model. The motion of an uncertain non-linear cardiovascular system has been solved considering second-order approximation, which also demonstrates the possibility of introducing spatial dimensions. Finally, the model's natural frequency expression has also been simulated and is composed of the previously published result.

Keywords: non-linear dynamical system; Hamiltonian dynamics; symmetric oscillator; cardiovascular muscle; action potential

\section{Introduction}

It has long been known that a linear system cannot entirely model the human cardiovascular system's activities as the heart rate is not a linear function or a constant [1,2]. The proper reason for the ECG signal variability is not clearly understood, making it an open research area. Cardiovascular signals contain [3] a considerable number of symmetric oscillatory components, which are unpredictable and not strictly periodic. It is more realistic to model the above system in a non-linear approach. One of the famous methods 
is the mass-spring-based non-linear modeling approach [4]. Some non-linear model under supply chain framework was studied by Sarkar [5] Tayyab et al. [6].

Days are gone when the Hodgkin-Huxley equation [7] was used to describe the non-linear equations, and the van der Pol approach had been used in the 20th century to design asymmetric relaxation oscillator for the study of conduction methods in the cardiovascular system [8,9]. A non-linear manufacturing model with inflation was solved by Sarkar et al. [10]. In the same direction, some non-linear manufacturing model under the consideration of reliability was developed by Sarkar [11] and Sarkar [12]. Here, the concept related to coupled symmetric oscillator has been introduced to represent the nonlinearity. This type of model played an essential role in the last recent years, along with the mass-spring-type model.

Hamiltonian mechanics is a sophisticated formulation of classical mechanics. This approach is generally used to represent the oscillating system in nature or involving very complex dynamical equations. Hamiltonian dynamics has a significant advantage in that it can represent a system that is coordinate independent. This concept of representation of the complex dynamical equation has been used in this work or the proposed model of cardiovascular conduction process is based on it as the model shows nonlinearity [13,14]. As a result, the non-linear spring constant can easily be changed depending on the environmental situation and simulated according to the design. A non-linear system can easily be represented in the well-known function technique, but the whole design or mathematical model must vary the spring constant. That is why Hamiltonian dynamics comes into the picture. The nonlinearity present in cardiovascular muscle dynamics has been studied in this work in Section 10. In the Hamiltonian approach of nonlinearity, the parameter accountable for nonlinearity has been changed. It is found that the variation of the spring constant does not affect the modeling.

Here, an attempt is taken using a modified van der Pol symmetric oscillator equation to design the above-proposed model. The work's beauty incorporates $[15,16]$ Hamiltonian approach towards the multiple coupled symmetric oscillators. It has also been used to find the amplitude-frequency relation for the two degrees of freedom of the proposed non-linear model [17]. A non-linear system for healthcare was developed by Jemai and Sarkar [18]. In this paper, using the Hamiltonian approach, the non-linear natural frequency has been calculated and simulated to develop the cardiovascular conduction system's dynamics.

\subsection{Review on Cardiovascular Conduction Process towards the Prosthetic Heart}

The study of the cardiovascular conduction process is significant for developing a prosthetic heart as the conduction process is a substantial part of the artificial heart. The development of modeling of cardiovascular conduction process and simulation technique of ECG signal faces numerous problems. This problem analysis improves the development process of a simulative model of ECG signal through research. This research analysis improvises the development process esthetically, depicted in a tabular forma given below in Table 1.

Table 1. A short literature review on the cardiovascular conduction process.

\begin{tabular}{cccc}
\hline $\begin{array}{c}\text { An Author with Reference } \\
\text { Number }\end{array}$ & Theme & Future Scope & Limitation \\
\hline Yamada [19] & $\begin{array}{c}\text { An implantable motor-driven } \\
\text { artificial heart was tested. }\end{array}$ & $\begin{array}{c}\text { The pump-based system } \\
\text { tested on some animals may } \\
\text { improve system efficiency. }\end{array}$ & $\begin{array}{c}\text { The control analogy of this } \\
\text { non-linear system is not } \\
\text { illustrated. }\end{array}$ \\
\hline Love [20] & $\begin{array}{c}\text { A mechanical, hydraulic } \\
\text { circulation system was tested } \\
\text { for developing an artificial } \\
\text { heart system. }\end{array}$ & $\begin{array}{c}\text { This mechanical circulation } \\
\text { system generates an initial } \\
\text { idea of the artificial heart. }\end{array}$ & $\begin{array}{c}\text { The system and control } \\
\text { dynamics is not mentioned. }\end{array}$ \\
\hline
\end{tabular}


Table 1. Cont.

\begin{tabular}{|c|c|c|c|}
\hline $\begin{array}{c}\text { An Author with Reference } \\
\text { Number }\end{array}$ & Theme & Future Scope & Limitation \\
\hline Kurita [21] & $\begin{array}{l}\text { The whole operation is } \\
\text { described as the development } \\
\text { of an artificial heart. }\end{array}$ & $\begin{array}{l}\text { Modification of the pump } \\
\text { system provides development } \\
\text { towards the artificial heart. }\end{array}$ & $\begin{array}{l}\text { The heart model's pumping } \\
\text { operation is proposed, but the } \\
\text { other operational parameters } \\
\text { are not considered. For } \\
\text { example, transportation delay, } \\
\text { nonlinearity }\end{array}$ \\
\hline Konieczny [22] & $\begin{array}{l}\text { The non-invasive pressure } \\
\text { monitoring system in an } \\
\text { artificial heart was proposed } \\
\text { and analyzed. }\end{array}$ & $\begin{array}{l}\text { The future scope is aimed at } \\
\text { the development of } \\
\text { non-invasive heart prostheses } \\
\text { or assistive devices. }\end{array}$ & $\begin{array}{l}\text { The pressure sensing } \\
\text { technique for various } \\
\text { conditions was not illustrated. }\end{array}$ \\
\hline Baldoni [23] & $\begin{array}{l}\text { A magnetic heart valve } \\
\text { sensing system was proposed } \\
\text { for tracking heart valve } \\
\text { prosthetic. }\end{array}$ & $\begin{array}{l}\text { The monitoring system will be } \\
\text { a step towards the } \\
\text { development of the entire } \\
\text { prosthetic heart monitoring } \\
\text { system }\end{array}$ & $\begin{array}{l}\text { The valve activity during } \\
\text { monitoring is elaborated in } \\
\text { this study, but the controlling } \\
\text { analogy is not exact. }\end{array}$ \\
\hline Rosli [24] & $\begin{array}{c}\text { A smart wireless heart } \\
\text { monitoring system was } \\
\text { developed that uses heartbeat } \\
\text { data for alarming. }\end{array}$ & $\begin{array}{l}\text { This system may recognize } \\
\text { the specific heart problem and } \\
\text { alert the medical person. }\end{array}$ & $\begin{array}{l}\text { The parametric analysis on } \\
\text { several critical factors like } \\
\text { system stability, sensitivity, } \\
\text { and reliability was not } \\
\text { pointed out. }\end{array}$ \\
\hline Marom [25] & $\begin{array}{l}\text { Three different Numerical } \\
\text { models of artificial heart } \\
\text { systems were developed in } \\
\text { the aspect of flow control. }\end{array}$ & $\begin{array}{l}\text { The various numerical model } \\
\text { may develop the artificial } \\
\text { model of the human heart. }\end{array}$ & $\begin{array}{l}\text { The proposed design is } \\
\text { incapable of generating a } \\
\text { transfer function analogy. }\end{array}$ \\
\hline Shi [26] & $\begin{array}{l}\text { The proposed artificial heart } \\
\text { model was based on physical } \\
\text { and numerical analysis. }\end{array}$ & $\begin{array}{l}\text { The actual artificial heart } \\
\text { model may be developed by } \\
\text { electrical and mathematical } \\
\text { analysis, comparing with a } \\
\text { simulative approach. }\end{array}$ & $\begin{array}{c}\text { Analysis of disease-related } \\
\text { issues with cardiovascular } \\
\text { system is depicted in this } \\
\text { article. }\end{array}$ \\
\hline Pohlmann [27] & $\begin{array}{l}\text { Some optimization techniques } \\
\text { were realized in the artificial } \\
\text { heart for optimal system } \\
\text { performance. }\end{array}$ & $\begin{array}{l}\text { The optimization technique } \\
\text { drives towards functional } \\
\text { improvement in the } \\
\text { development of the artificial } \\
\text { heart. }\end{array}$ & $\begin{array}{l}\text { Optimization parameters of } \\
\text { artificial heart modeling } \\
\text { systems have not been } \\
\text { considered. }\end{array}$ \\
\hline
\end{tabular}

\subsection{Importance of van der Pol Equation}

In practical, almost all the system behaves like a non-linear system. For analyzing a non-linear system, the basic equation is modified using the van der Pol equation. Without this equation, it is challenging to study any basic non-linear symmetric oscillator system. Here, in this study, a non-linear symmetric oscillator-based approach is used to represent a cardiovascular muscle. That is why the van der Pol equation is used here.

\subsection{Why Hamiltonian Approach}

The Hamiltonian operator is nothing but an energy operator that represents the total energy of a system. As energy cannot be created or destroyed, the concept of conservation of energy can be applied for both linear and non-linear systems. In this study, the modeling of the cardiovascular conduction process is shown in a non-linear way. The Hamiltonian approach is used to represent the overall nonlinearity. Hamiltonian dynamics' main advantage is that it is coordinate independent, so the non-linear spring constant can easily be varied and simulated according to one's wishes. 


\subsection{Background and Related Work}

In the artificial heart pumping system, a suitable heartbeat has been maintained using medium-speed motor that pumps the blood very efficiently (Frazier, 1994). The process of blood circulation was clearly described, with most transportation delay time with $1 \mathrm{~ms}$. The goal was to accomplish the desired step response that contains less than $4 \%$ and $9 \%$ steady-state error, overshoot, respectively. The use of a controller has improved the system characteristics. Researchers started working on the Study and Analysis of the Human Cardiovascular system in 1940, while in 2004, VAD had been patented for uninterrupted blood flow (Choi and Min, 2014). From previous research work, it has been observed that the cardiovascular conduction process in the ventricular assist device was incorporated and had also been modified so many times considering the activities of cardiovascular muscle in a linear approach. Sustainable practice in the healthcare system was studied by Jemai et al. In this direction, a non-linear smart system was developed by Dey et al. Implementation of the artificial lower limb under non-linear stability was proposed by Das et al. Herbal medicines have a good impact described by Garai et al. The natural or essential cardiovascular muscle behavior was modeled using some necessary elementary substances like mass and spring, and those were considered a linear element. However, ECG that generates from cardiovascular muscle is indeterministic. A flower pollination algorithm was developed by Sahaet al. [28]. to maintain any machine. So, an ambiguity comes between the theoretical result and experimental result. These elements (mass and spring) do not show linearity when it goes under a real-life experiment or used in some implementation. One of the reasons is transportation delay in any practical system (it is also called nonzero reaction time); nonlinearity comes into the picture. Cardiac muscle also has nonzero reaction time, due to which the overall model becomes non-linear. Here, in our work, a complete non-linear symmetric oscillator model using the Hamiltonian approach has been used to represent the energy of the cardiovascular conduction system's dynamics in a non-linear way.

\subsection{Contributions and Organization}

For describing the non-linear dynamics of the cardiovascular conduction system, modeling is necessary, representing the system's activities. Here, a complete non-linear symmetric oscillator-based model using the Hamiltonian approach has been developed to describe the cardiovascular conduction system dynamics in a non-linear way $[29,30]$. Reality shows the nonlinearity of spring and damper. The above-discussed transport delay in the cardiovascular conduction system is mainly responsible for making the overall designed model non-linear. As the non-linear system does not obey the additivity and homogeneity property, its overall energy must be represented. The proposed non-linear cardiovascular conduction system's total energy is characterized by Hamiltonian dynamics, as it talks about the system energy. Finally, for the validation of the model, simulation of the non-linear model has been done considering different spring constant values.

Modified van der Pol equation has been used for model formation. How the real work has been organized is given below. Initially, the modified van der Pol equation was used for model formation, where spring is considered a non-linear element in Section 2. Hamiltonian dynamics is described for the linear mass-spring model, which is unable to explain the nonlinearity. So, in Section 3, Hamiltonian dynamics is again applied for the non-linear model. Due to the loading effect, the Hamiltonian approach is also tested for the series connection of two mass-spring models in Section 5. The degree of freedom has also been determined by varying the spring constant, simulation is done for our proposed design, which shows periodicity and proves that the proposed model is correct as the ECG signal is periodic. The phase portrait of the model has also been simulated. It is found from the simulation aspect that state point came closer to the saddle point, which ensures the stability of the proposed design. 


\subsection{General Objective of the Study}

In this study, a non-linear symmetric oscillator-based model using the Hamiltonian approach has been developed to explain overall the cardiovascular conduction system dynamics in a non-linear way, which is better than describing the function approach of nonlinearity. In the proposed modeling, the nature of nonlinearity is found among spring and damper. Lag phase or slow time introduces nonlinearity within the model. However, the proposed design of the entire cardiovascular conduction process has been formulated using the Hamiltonian approach, and after simulation, it was found that the design gives stability. Here, a two-dimensional phase portrait of the proposed design considering different initial conditions has been tested. At the same time, the three-dimensional phase portrait for the proposed method has also been depicted. From all the phase portraits, it is observed that the system is stable towards the proposed design. A detailed explanation of the simulation result is given in the Section 8.

\section{Modified Symmetric Oscillator Equation-Based Non-Linear Model of the Proposed Design}

The following notation is utilized for the modelling of this study. Table 2 is given below, representing the parameters used in the entire work.

Table 2. Parameter used in the implementation.

\begin{tabular}{|c|c|c|}
\hline Symbol & Meaning & Unit \\
\hline$\beta$ & Damping constant & $\mathrm{lbfs} /$ inch \\
\hline$\sigma$ & Constant of van der Pol model & NA \\
\hline $\mathrm{x}$ & Displacement & $\mathrm{cm}$ \\
\hline$\dot{\mathrm{x}}$ & Velocity & $\mathrm{cm} / \mathrm{s}$ \\
\hline$X$ & The amplitude of input sinusoidal signal for non-linear analysis & V \\
\hline M & The distance between nodes & $\mathrm{mm}$ \\
\hline $\mathrm{Y}$ & The output of the non-linear system & V \\
\hline M & Mass of cardiovascular muscle & g \\
\hline K & Spring constant & $\mathrm{N} / \mathrm{m}$ \\
\hline B & Viscous drug & $\mathrm{P}$ \\
\hline $\mathrm{N}$ & Order of spring constant & NA \\
\hline K & The slope of non-linear section & NA \\
\hline$\delta_{\mathrm{ij}}$ & Kronecker delta & NA \\
\hline KE & Kinetic energy & $\mathrm{J}$ \\
\hline $\mathrm{PE}$ & Potential energy & $\mathrm{J}$ \\
\hline Px & Momentum & $\mathrm{kg} \cdot \mathrm{m} / \mathrm{s}$ \\
\hline $\mathrm{H}$ & Hamiltonian operator & NA \\
\hline$\hat{\mathrm{H}}(\mathrm{v})$ & Hamiltonian considering multiple inputs & NA \\
\hline $\mathrm{L}$ & Lagrangian operator & NA \\
\hline$\omega$ & Angular frequency & $\mathrm{rad} / \mathrm{s}$ \\
\hline $\mathrm{T}$ & Period & $\mathrm{s}$ \\
\hline$\Phi$ & Phase shift & $\mathrm{rad}$ \\
\hline $\mathrm{V}$ & Describing function & NA \\
\hline $\mathrm{B}_{\mathrm{n}}$ & Amplitude of oscillation & $\mathrm{V}$ \\
\hline
\end{tabular}


The Van der Pol symmetric oscillator is nothing but a primary type of non-linear symmetric oscillator used to represent any non-linear model. Our cardiac muscle (a part of the cardiovascular conduction system) can also be described as a non-linear symmetric oscillator. So, it is represented in terms of a modified van der Pol symmetric oscillatorbased equation. The Hamiltonian approach is used to describe the nonlinearity in words of energy. Here, non-linear symmetric oscillator is used to represent the cardiovascular conduction system [31] toproduce its fundamental behavior. The non-linear dynamical equation of the modified van der Pol symmetric oscillator is given below.

$$
\frac{d^{2} x}{d t^{2}}+\beta\left(x^{2}-\sigma\right) \frac{d x}{d t}+\omega_{0}^{2} \cdot x=F(t)
$$

Here, " $\sigma$ " is taken 1 for vander Pol non-linear Model.

Equation (1) has been modified and given in a general form to maintain the symmetric oscillator's constant amplitude and synchronize the intrinsic frequency.

$$
\frac{d^{2} x}{d t^{2}}+\beta\left(x^{2}-\sigma\right) \frac{d x}{d t}+x(x+m) \cdot(x+n m) / m n=0,
$$

where $\mathrm{m}$ is the distance between nodes and $\mathrm{n}$ is an integer always taken positively in this model.

At $x=-m$, saddle point or breakaway point occurs.

At $x=-n \cdot m$, the stable node is found for every positive value of $n$. Here, " $n$ " represents integers.

In the previous work [32], the above equation was only tested for only $n=2$. However, the above modification has drastically changed the properties and the stability of the whole system after considering the value of $\mathrm{n}$ greater than 2 . With the repetitive experiments, it is seen that the system gives optimum stability at $n=4$. The simulation result has also been observed that the simulated distance between saddle point nodes is fixed. A new parameter $(\gamma)$ has been introduced in this model to varying the distance [33]. The mathematical equations are needed to introduce $(\gamma)$ are given below.

$$
\begin{gathered}
\dot{\mathrm{x}_{\mathrm{i}}}=\mathrm{y}_{1} \\
\dot{\mathrm{y}}_{\mathrm{i}}=\mathrm{f}\left(\mathrm{x}_{\mathrm{i}}, \mathrm{y}_{\mathrm{i}}\right) .
\end{gathered}
$$

Considering the above modification $\dot{y}_{i}$ can be written in terms of $f\left(x_{i}, y_{i}\right)$, where $f\left(x_{i}\right.$, $\mathrm{y}_{\mathrm{i}}$ ) is given as follows.

$$
f\left(x_{i}, y_{i}\right)=-\beta_{i}\left(x_{i}^{2}-\sigma_{i}\right) y_{i}-f_{i} x_{i}\left(x_{i}+\gamma_{i}\right)\left(x_{i}+m_{i}\right) .
$$

The other difficulty with the previous model is that the fixation of amplitude means amplitude could not be controlled. In our proposed design, by varying the parameter $\sigma$, the system amplitude has also been maintained. It is seen from the simulation result that simulation curves come and move closer to the saddle point, which is the most essential desired result towards the non-linear model of the cardiovascular system. All simulation results are given later in the Section 8.

\section{Hamiltonian Approach for Linear System}

The general formula to find the degree of freedom of any system is given by ( $3 \mathrm{~N}$ M) $[34,35]$ where $M$ is number of constrains and $N$ is denoted by the number of free particles. For example, on the sphere, the degree of freedom is $(3 \times 1-1)=2$, whereas, for a simple pendulum, the degree of freedom is $(3 \times 1-2)=1$ as the number of constrains is 2(angel of deflection and sufficient length). Similarly, our proposed non-linear symmetric oscillatory model towards the cardiovascular system's conduction is also having more than two degrees of freedom, which possess some advantages as the number of independent 
coordinates is less. A PID controller with two degrees of freedom would have related to the proposed design in the future. It would have been able to reject the disturbances quickly. Newtonian mechanics (1670) reformulated progressively in the 1800 centuries made solutions to a far greater number of problems. It was first constructed in 1780 by scientist Lagrange and then again reformulated by William. R. Hamilton in 1830 . The Lagrangian mechanics is based on the difference of kinetic energy and potential energy usually written in terms of position and velocity. Still, the Hamiltonian mechanics [36,37] is generally written in the momentum and position form. In some previous research work, the cardiovascular system model was represented by a frictionless mass-spring mechanical system where the model was considered a linear system. Figure 1 illustrates the system, as mentioned earlier, is given below.

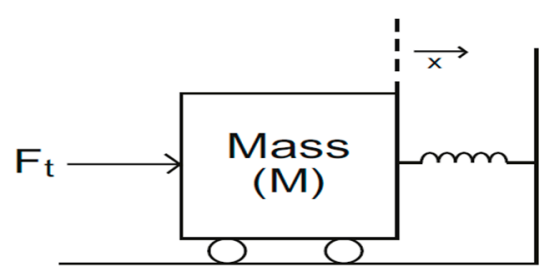

Figure 1. Mass-spring linear model of cardiovascular wall.

To find the Lagrangian and Hamiltonian expression for the above model, in which " $F(t)$ " denotes the applied force on the mass, " $x$ " represents displacement, and " $m$ " $e x-$ presses the model's mass $\mathrm{k}$ means spring constant. KE is given by $\frac{1}{2} \mathrm{~m} \mathrm{x}^{2}$. That represents the energy due to the motion of the system while the $P E=-\int_{\alpha}^{x}(-k x) d x=\frac{1}{2} k x^{2}$.

So, the Lagrangian L can be calculated [21] as

$$
\begin{gathered}
\mathrm{L}=\mathrm{KE}-\mathrm{PE} \\
\mathrm{L}=\frac{1}{2} \mathrm{mx}^{2}-\frac{1}{2} \mathrm{kx}^{2} .
\end{gathered}
$$

Considering $\mathrm{Px}=\mathrm{m} \dot{\mathrm{x}}$, Equation (7) can be written as

$$
\mathrm{L}=\frac{\mathrm{P}_{\mathrm{x}}^{2}}{2 \mathrm{~m}}-\frac{1}{2} \mathrm{k} \mathrm{x}^{2}
$$

Hence, the generalized momentum

$$
\begin{gathered}
P x=\frac{\partial \mathrm{L}}{\partial \dot{x}}=m \dot{x} \\
\dot{x}=\frac{P_{x}}{m} .
\end{gathered}
$$

In terms of Hamiltonian

$$
H=\sum \mathrm{P}_{\mathrm{j}} \dot{\mathrm{q}}_{\mathrm{j}}-\mathrm{L}
$$

where $P_{j}$ is generalized momentum and $\dot{q}_{j}$ is generalized velocity. Finally, the expression of $\mathrm{H}$ becomes

$$
\begin{gathered}
H=P_{x} \dot{x}-L \\
H=P_{x} \frac{P_{x}}{m}-\left(\frac{P_{x}^{2}}{2 m}-\frac{1}{2} K x^{2}\right) \\
H=\frac{P_{x}^{2}}{2 m}+\frac{1}{2} K x^{2} .
\end{gathered}
$$


So Hamiltonian H represents the total energy, and the equation of motions is framed below.

$$
\begin{gathered}
\dot{x}=\frac{\partial H}{\partial \dot{P}_{x}}=\frac{P_{x}}{m} \\
\dot{P}_{x}=-\frac{\partial H}{\partial \dot{x}}=-k x .
\end{gathered}
$$

Multiplying Equation (15) by $\mathrm{m}$ and then comparing with Equation (16), it can be written as

$$
\dot{P}_{x}=m \ddot{x}=\cdots \frac{d}{d t}(m \dot{x})
$$

Again, it is known to us that $\dot{P}_{x}=-K . x$, thus, rearranging this equation,

$$
\begin{gathered}
\dot{P_{x}}+k \cdot x=0 \\
\frac{d}{d t}(m \dot{x})+k \cdot x=0 \\
\ddot{x}+\left(\frac{k}{m}\right) x=0 \\
\ddot{x}+\omega^{2} x=0,
\end{gathered}
$$

where $\omega=\sqrt{\frac{\mathrm{k}}{\mathrm{m}}}$ The natural frequency.

The period of oscillation is also given by

$$
\mathrm{T}=\frac{2 \pi}{\omega}=2 \pi \sqrt{\frac{\mathrm{k}}{\mathrm{m}}} .
$$

\section{Hamiltonian Approach for Non-Linear System}

For explaining the essential dynamic characteristics of a vibrating system quickly, one degree of freedom can generally be modeled. However, when two cells of the cardiovascular wall [38,39] are connected in series, it should be represented as a non-linear system having two degrees of freedom. In this section, the symmetric oscillator has thoroughly been analyzed using the Hamiltonian approach is given below.

$$
\mathrm{m}_{\mathrm{j}} \delta_{\mathrm{ij}} \ddot{\mathrm{x}_{\mathrm{i}}}+\mathrm{f}\left(\mathrm{x}_{1}, \mathrm{x}_{2}, \ldots, \mathrm{x}_{\mathrm{n}}\right)=0 .
$$

where $\delta_{\mathrm{ij}}$ is called Kronecker delta.

By the Hamiltonian approach, the system Hamiltonian $\mathrm{H}$ can be written as

$$
H\left(x_{1}, x_{2}, \ldots \ldots, x_{n}\right)=\frac{1}{2} \sum_{j=1}^{n} m_{j} x_{i}^{2}+F\left(x_{1}, x_{2}, \ldots \ldots, x_{n}\right),
$$

where $T=\frac{2 \pi}{\omega}$. It denotes the time of the non-linear modeled symmetric oscillator. So, the potential energy is given by

$$
\mathrm{KE}=\frac{1}{2} \sum_{\mathrm{j}=1}^{\mathrm{n}} \mathrm{m}_{\mathrm{j}} \mathrm{x}_{\mathrm{i}}^{2} \text { and } \mathrm{PE}=\mathrm{F}\left(\mathrm{x}_{1}, \mathrm{x}_{2}, \ldots \ldots, \mathrm{x}_{\mathrm{n}}\right) .
$$

As the Hamiltonian approach is suitable for the conservative systems, the total energy remains the same during the movement of an uncertain non-linear [40] model related to the human cardiovascular system.

$$
\mathrm{H}=\mathrm{PE}+\mathrm{KE} \text {. }
$$


Taking integration of Equation (24), a new function $\hat{H}(\mathrm{v})$ has been defined describing the energy of the system considering multiple inputs and given below.

$$
\hat{\mathrm{H}}\left(\mathrm{x}_{1}, \mathrm{x}_{2}, \ldots . ., \mathrm{x}_{\mathrm{n}}\right)=\int_{0}^{\frac{\mathrm{T}}{4}} \frac{1}{2}\left[\sum_{j=1}^{\mathrm{n}} \mathrm{m}_{\mathrm{j}} \mathrm{x}_{\mathrm{j}}^{2}+\mathrm{F}\left(\mathrm{x}_{1}, \mathrm{x}_{2}, \ldots ., \mathrm{x}_{\mathrm{n}}\right)\right] \mathrm{dt}=\frac{\mathrm{T}}{4} \mathrm{H}_{0} .
$$

For simplicity, a sinusoidal form-based displacement is taken to describe the dynamics approximately.

$$
x_{j}(t)=B_{n} \cos \omega t,
$$

where $B_{n}$ is the generalized varying amplitude, where $n$ varies from 1 to $N$ and $\omega$ denotes the angular frequency for the oscillation [41]. Putting the value of (28) into (27) $\hat{H}$ can be written as follows.

$$
\begin{aligned}
\hat{\mathrm{H}}\left(\mathrm{B}_{1}, \mathrm{~B}_{2}, \ldots \ldots, \mathrm{B}_{\mathrm{N}}, \omega\right)= & \int_{0}^{\mathrm{T}}\left[\frac{1}{2} \omega^{2} \sin ^{2}(\omega \mathrm{t}) \sum_{\mathrm{j}=1}^{\mathrm{n}} \mathrm{m}_{\mathrm{j}} \mathrm{B}_{\mathrm{i}}+\mathrm{F}\left(\mathrm{B}_{1} \cos \omega \mathrm{t}+\mathrm{B}_{2} \cos \omega \mathrm{t}+\right.\right. \\
& \left.\left.\cdots+\mathrm{B}_{\mathrm{N}} \cos \omega \mathrm{t}\right)\right] \mathrm{dt}=\frac{\mathrm{T}}{4} \mathrm{H}_{0} .
\end{aligned}
$$

\section{Modeling of the Proposed Design}

In this section, the series connection of two mass-spring models [42,43] is taken together, and the Hamiltonian approach analyzes the nonlinearity. Series connection of two cardiovascular muscle cells is represented as cardiac fiber, or a muscle is a chain connection of cardiac cells. Modeling one cell can be described in a linear approach, but two cells loading effect series connection cannot be represented by a linear model [44]. That is why the Hamiltonian method is introduced. The following Figure 2 describes the non-linear proposed model to explain the human cardiovascular system's conduction process.

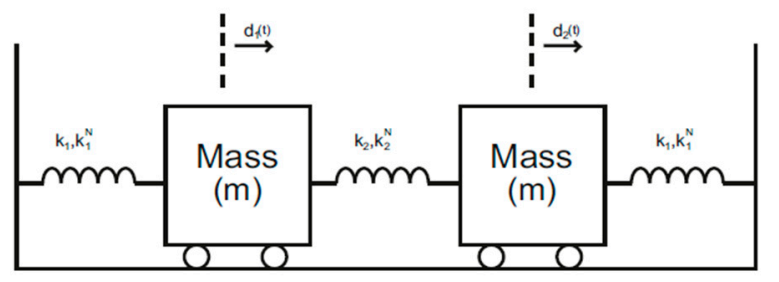

Figure 2. Two degrees of freedom (DOF) mass-spring non-linear system.

Here, $k_{1}$ and $k_{2}$ represents the linear coefficient of spring, whereas $k_{1}{ }^{N}$ and $k_{2} N$ represents the non-linear coefficient of spring. $\mathrm{d} 1$ and $\mathrm{d} 2$ represent the displacement of mass M. Applying Hamiltonian $\mathrm{H}$ to the system $\hat{H}$ can be written as

$$
\begin{gathered}
\hat{\mathrm{H}}(\mathrm{d} 1, \mathrm{~d} 2)=\frac{1}{2} \int_{0}^{\frac{\mathrm{T}}{4}}\left[\mathrm{Md}_{1}^{2}+\mathrm{Md}_{2}^{2}+\mathrm{K}_{1} \mathrm{M}_{1}^{2}+\frac{1}{2} \mathrm{k}_{1} \mathrm{~N}_{1} \mathrm{~d}_{1}^{4}+\mathrm{k}_{2}\left(\mathrm{~d}_{1}-\mathrm{d}_{2}\right)^{2}+\right. \\
\left.\frac{1}{2} \mathrm{k}_{2} \mathrm{~N}^{2}\left(\mathrm{~d}_{1}-\mathrm{d}_{2}\right)^{4}+\mathrm{k}_{1} \mathrm{~d}_{2}{ }^{2}+\frac{1}{2} \mathrm{k}_{1} \mathrm{~N}_{\mathrm{d}_{2}}{ }^{4}\right] \mathrm{dt} .
\end{gathered}
$$

Considering the first-order approximate solution in the sinusoidal form, $d_{1}=B_{1} \cos \omega t$ and $d_{2}=\left(B_{1}-B\right) \cos \omega t$ and then putting the value $d_{1}(t)$ and $d 2(t)$ in Equation $(30), \hat{H}$ can be written as given below.

$$
\begin{gathered}
\hat{\mathrm{H}}(\mathrm{BO}, \mathrm{B} 1, \omega)=\frac{1}{2} \int_{0}^{\frac{\mathrm{T}}{4}}\left\{\mathrm{M} \omega^{2}\left[\mathrm{~B}_{1}{ }^{2}+\left(\mathrm{B}_{1}-\mathrm{B}_{0}\right)^{2}\right] * \sin ^{2}(\omega \mathrm{t})+\frac{1}{2} \mathrm{~B}_{1}{ }^{2} \cos ^{2}(\omega \mathrm{t})+\right. \\
\frac{1}{2} \mathrm{k}_{1}{ }^{N} \mathrm{~B}_{1}{ }^{4} \cos ^{4}(\omega \mathrm{t})+\mathrm{k}_{2}\left[\mathrm{~B}_{1} \cos \omega \mathrm{t}-\left(\mathrm{B}_{1}-\mathrm{B}_{0}\right) \cos ^{2}(\omega \mathrm{t})\right]+\mathrm{k}_{2}{ }^{\mathrm{N}}\left[\mathrm{B}_{1} \cos \omega \mathrm{t}-\right. \\
\left.\left.\left(\mathrm{B}_{1}-\mathrm{B}_{0}\right) \cos \omega \mathrm{t}\right]^{4}+\left(\mathrm{B}_{1}-\mathrm{B}_{0}\right)^{2} \mathrm{k}_{1} \cos ^{2}(\omega \mathrm{t})+\frac{1}{2}\left(\mathrm{~B}_{1}-\mathrm{B}_{0}\right)^{4} \mathrm{k}_{1}{ }^{\mathrm{N}} \cos ^{4}(\omega \mathrm{t})\right\} \mathrm{dt} .
\end{gathered}
$$

Taking the first derivative of the above equation and making equals zero for getting the frequency of oscillation. 
The frequency amplitude relation has been established and given below.

$$
\begin{gathered}
4 \mathrm{~B}_{1} \mathrm{k}_{1}+9 \mathrm{~A}_{2} \mathrm{~B}_{1} \mathrm{k}_{1}{ }^{\mathrm{N}}+3 \mathrm{~B}_{1} \mathrm{k}_{1}{ }^{\mathrm{N}}-3 \mathrm{~B}_{0} 3\left(\mathrm{k}_{1}{ }^{\mathrm{N}}+\mathrm{k}_{2}{ }^{\mathrm{N}}\right)-4 \mathrm{~B}_{1} \mathrm{M} \omega^{2} \\
-\mathrm{B}\left(4 \mathrm{k} 1+4 \mathrm{k} 2+9 \mathrm{~B}_{1}{ }^{2} \mathrm{k}_{1}{ }^{\mathrm{N}}-4 \mathrm{M} \omega^{2}\right)=0 .
\end{gathered}
$$

The above equation can be rearranged as follows:

$$
\left(\mathrm{B}_{0}-2 \mathrm{~B}_{1}\right)\left(4 \mathrm{k}_{1}+3 \mathrm{~B}_{0} \mathrm{k}_{1}{ }^{\mathrm{N}}+3 \mathrm{~B}_{0} \mathrm{~B}_{1} \mathrm{k}_{1}{ }^{\mathrm{N}}+3 \mathrm{~B}_{1}{ }^{2} \mathrm{k}_{1}{ }^{\mathrm{N}}-4 \mathrm{M} \omega^{2}\right)=0 .
$$

Combining Equations (32) and (33) $\omega(\mathrm{B})$

$$
\omega\left(B_{0}\right)=\frac{1}{4} \sqrt{\frac{32 \mathrm{k}_{2}+16 \mathrm{k}_{1}+3 \mathrm{~B}_{0}^{2} \mathrm{k}_{1} \mathrm{~N}+24 \mathrm{k}_{2} \mathrm{~N}^{\mathrm{N}} \mathrm{B}_{0}^{2}}{\mathrm{M}}} .
$$

Special cases:

$$
\begin{aligned}
& \text { a. For } \mathrm{k}_{1}=0, \mathrm{k}_{1}{ }^{\mathrm{N}}=0, \omega\left(\mathrm{B}_{0}\right)=\frac{1}{4} \sqrt{\frac{32 \mathrm{k}_{2}+24 \mathrm{~B}_{0}^{2} \mathrm{k}_{2} \mathrm{~N}}{\mathrm{M}}} \\
& \text { b. For } \mathrm{k}_{2}{ }^{\mathrm{N}}=0, \omega\left(\mathrm{B}_{0}\right)=\frac{1}{4} \sqrt{\frac{32 \mathrm{k}_{2}+16 \mathrm{k}_{1}+3 \mathrm{~B}_{0}^{2} \mathrm{k}_{1} \mathrm{~N}}{\mathrm{M}}} .
\end{aligned}
$$

For more accurate results, $d 1(t)$ and $d 2(t)$ have been formulated for simulation in sinusoidal form and are shown below:

$$
\begin{aligned}
& \mathrm{d}_{1}(\mathrm{t})=\mathrm{B}_{3} \cos \omega_{2} \mathrm{t}+\left(\mathrm{B}_{2}-\mathrm{B}_{3}\right) \cos 3 \omega_{2} t \\
& \mathrm{~d}_{2}(\mathrm{t})=\mathrm{B}_{5} \cos \omega_{2} \mathrm{t}+\left(\mathrm{B}_{4}-\mathrm{B}_{5}\right) \cos 3 \omega_{2} \mathrm{t} .
\end{aligned}
$$

As cardiovascular muscle does not consist of one or two cells, preferably $\mathrm{Z}$ number of cells connected in series should be used to design cardiovascular muscle dynamics $[45,46]$. When only one cell is considered, it has been observed that the degree of freedom (DOF) is $1(3 \times 1-2=1)$, whereas it will be two if two cells are connected in series as several constraints are four $(3 \times 2-4=2)$. The degree of freedom can be determined in three cells using the same formula, three $(3 \times 3-6=3)$. It means if the $Z$ number of cells are connected in series, the degree of freedom will be Z. So, Equation (30) will be working correctly without any difficulties with a variable $\mathrm{Z}$.

\section{Generation of Action Potential and Coupling of Nodes}

When the cell membrane crosses a specific threshold value or threshold potential, an action potential is generated $[47,48]$ across the cell wall. Current is flowing due to this action potential [49] in or out of the cell. Spontaneous depolarization is one of the essential properties of the cardiac conduction system. The action potential is automatically generated in this system without external input. The degree of an action potential depends on how fast the depolarization occurs. However, in our proposed design considering unidirectional coupling, the term for the mass-spring non-linear model is (k1d1-k2d2) used for action potentials. The difference in coefficient tells us the asymmetry in the collar. Initially, to observe the interaction between two nodes, $\mathrm{k} 1$ and $\mathrm{k} 2$ have been considered equal to one. Finally, by varying the value of $\mathrm{k} 1$ and $\mathrm{k} 2$, different coupling simulation result has been observed and given in the next section.

\section{Muscle Dynamics Traditional Describing Function Method to Determine Nonlinearity}

The describing function technique can describe the non-linear behavior of any nonlinear system in control system engineering $[49,50]$. This method has also been used. This method is nothing but a frequency domain analysis related to the system. This technique is also called the "describing function analysis technique," whose mathematical 
representation can be given as $\mathrm{V}(\mathrm{V}, \omega)=\frac{\mathrm{Y}_{1}}{\mathrm{X}} \angle \Phi$. Now this, " $\Phi$ " denotes overall phase shift. Figure 3 represents the simple block of the above analysis technique.

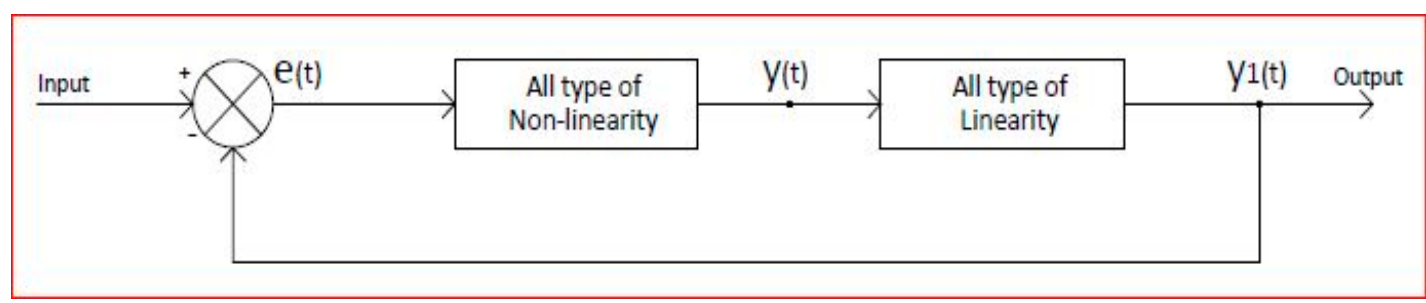

Figure 3. Basic block diagram of non-linear analysis through describing the function.

It has already been explained that response (i/p vs. o/p) of cardiovascular muscle shows a finite dead zone followed by constant in Figure 4 .

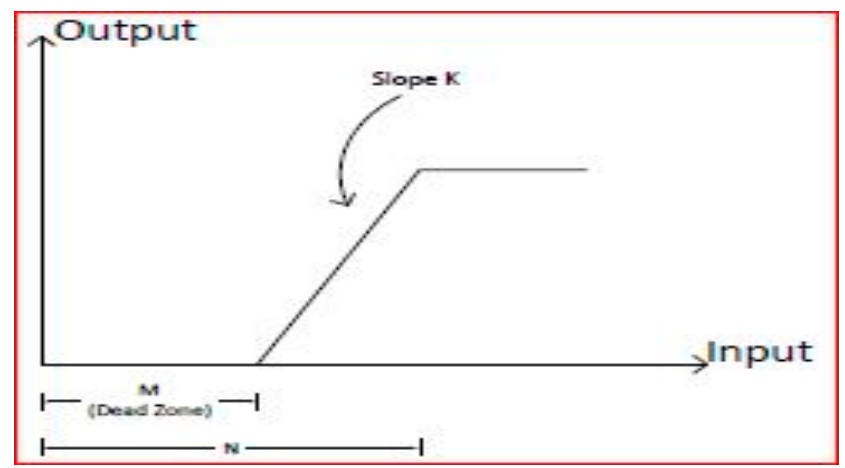

Figure 4. Input-output characteristics of the proposed design. by

Let incoming signal is given by $\mathrm{x}(\mathrm{t})=\mathrm{X} \sin \omega \mathrm{t}$, and due to this, input-output is given

$$
\begin{aligned}
\mathrm{y} & =0, \text { for } 0 \leq \omega \mathrm{t} \leq \theta 1 \\
& =\mathrm{K} .\left(\mathrm{x}-\frac{\mathrm{M}}{2}\right), \text { for } \theta 1 \leq \omega \mathrm{t} \leq \theta 2, \\
& =\mathrm{K} .\left(\mathrm{V}-\frac{\mathrm{M}}{2}\right), \text { for } \theta 2 \leq \omega \mathrm{t} \leq(\pi-\theta 2), \\
& =\mathrm{K} .\left(\mathrm{V}-\frac{\mathrm{M}}{2}\right), \text { for }(\pi-\theta 2) \leq \omega \mathrm{t} \leq(\pi-\theta 1), \\
& =0, \text { for }(\pi-\theta 1) \leq \theta 1,
\end{aligned}
$$

$$
\begin{gathered}
A_{1}=\frac{2}{\pi}\left[\int_{\theta 1}^{\theta 2} K\left(X \cdot \operatorname{Sin} \omega t-\frac{M}{2}\right) \cos \omega t d(\omega t)+\int_{\theta 2}^{\pi-\theta 2} K\left(s-\frac{M}{2}\right) \cos \omega t d(\omega t)+\right. \\
\left.\int_{\pi-\theta 2}^{\pi-\theta 1} k\left(X \cdot \operatorname{Sin} \omega t-\frac{M}{2}\right) \cos \omega t d(\omega t)\right]
\end{gathered}
$$

$\mathrm{A}_{1}=\frac{2 \mathrm{~K}}{\pi}\left[\frac{\mathrm{x}}{2} \int_{\theta 1}^{\theta 2} 2 \sin \omega \mathrm{t} \cdot \cos \omega \mathrm{t} \mathrm{d}(\omega \mathrm{t})\right.$

$-\frac{\mathrm{M}}{2} \int_{\theta 1}^{\theta 2} \cos \omega \mathrm{t} d(\omega \mathrm{t})+\left(\mathrm{N}-\frac{\mathrm{M}}{2}\right) \int_{\theta 2}^{\pi-\theta 2} \cos \omega \mathrm{t} \mathrm{d}(\omega \mathrm{t})$

$$
\left.+\frac{\mathrm{X}}{2} \int_{\pi-\theta 2}^{\pi-\theta 1} 2 \sin \omega \mathrm{t} \cdot \cos \omega \mathrm{t} d(\omega \mathrm{t})-\frac{\mathrm{M}}{2} \int_{\pi-\theta 2}^{\pi-\theta 1} \cos \omega \mathrm{t} \mathrm{d}(\omega \mathrm{t})\right]
$$

$$
\begin{aligned}
\mathrm{A}_{1} & =\frac{2 \mathrm{~K}}{\pi}\left[\frac{\mathrm{X}}{2} \int_{\theta 1}^{\theta 2} 2 \sin \omega \mathrm{t} \cdot \mathrm{d}(\omega \mathrm{t})\right. \\
& \left.-\frac{\mathrm{M}}{2} \int_{\theta 1}^{\theta 2} \cos \omega \mathrm{td}(\omega \mathrm{t})+\left(\mathrm{s}-\frac{\mathrm{M}}{2}\right) \int_{\theta 2}^{\pi-\theta 2} \cos \omega \mathrm{td}(\omega \mathrm{t})+\frac{\mathrm{X}}{2} \int_{\pi-\theta 2}^{\pi-\theta 1} \sin 2 \omega \mathrm{t} \cdot \mathrm{d}(\omega \mathrm{t})-\frac{\mathrm{M}}{2} \int_{\pi-\theta 2}^{\pi-\theta 1} \cos \omega \mathrm{t} \mathrm{d}(\omega \mathrm{t})\right] \\
\mathrm{A}_{1} & =0 .
\end{aligned}
$$

Now the value of $B_{1}$ has to be calculated and given as follows.

$$
\mathrm{B}_{1}=\frac{2}{\pi} \int_{0}^{\pi} \mathrm{y}(\mathrm{t}) \sin \omega \mathrm{t} \cdot \mathrm{d}(\omega \mathrm{t})
$$




$$
\begin{gathered}
\mathrm{B}_{1}=\frac{2}{\pi}\left[\int_{\theta 1}^{\theta 2} \mathrm{~K}\left(\mathrm{X} \sin \omega \mathrm{t}-\frac{\mathrm{M}}{2}\right) \sin \omega \mathrm{t} \cdot \mathrm{d}(\omega \mathrm{t})\right. \\
+\int_{\theta 2}^{\pi-\theta 2} \mathrm{~K}\left(\mathrm{~N}-\frac{\mathrm{M}}{2}\right) \sin \omega \mathrm{t} \mathrm{d}(\omega \mathrm{t}) \\
\left.\quad+\int_{\pi-\theta 2}^{\pi-\theta 1} \mathrm{~K}\left(\mathrm{X} \sin \omega \mathrm{t}-\frac{\mathrm{M}}{2}\right) \sin \omega \mathrm{td}(\omega \mathrm{t})\right] \\
\mathrm{B}_{1}=\frac{2 \mathrm{~K}}{\pi}\left[\int_{\theta 1}^{\theta 2} \mathrm{X} \sin ^{2} \omega \mathrm{t} \cdot \mathrm{d}(\omega \mathrm{t})\right. \\
-\int_{\theta 1}^{\theta 2}-\frac{\mathrm{M}}{2} \sin \omega \mathrm{t} \mathrm{d}(\omega \mathrm{t})+\left(\mathrm{s}-\frac{\mathrm{M}}{2}\right) \int_{\theta 2}^{\pi-\theta 2} \sin \omega \mathrm{td}(\omega \mathrm{t}) \\
\left.+\mathrm{X} \int_{\pi-\theta 2}^{\pi-\theta 1} \sin ^{2} \omega \mathrm{t} \cdot \mathrm{d}(\omega \mathrm{t})-\frac{\mathrm{M}}{2} \int_{\pi-\theta 2}^{\pi-\theta 1} \sin \omega \mathrm{t} \mathrm{d}(\omega \mathrm{t})\right] \\
\mathrm{B}_{1}=\frac{2 \mathrm{~K}}{\pi}\left[\mathrm{X} \cdot \theta 2-\mathrm{X} \cdot \theta 1-\frac{\mathrm{X}}{2} \sin 2 \theta 2+\frac{\mathrm{X}}{2} \sin 2 \theta 1+2 \mathrm{~V} \cos \theta 2-\mathrm{M} \cos \theta 1\right] .
\end{gathered}
$$

As input is $x(t)=X \cdot \sin \omega t$, and at $\omega t=\theta 1$, amplitude is $\frac{M}{2} \cdot M=2 X \sin \theta 1$. So, $\sin \theta 1=\frac{\mathrm{M}}{2 \mathrm{X}}$.

Similarly, at $\omega t=\theta 2$, the amplitude is s. So $V=X \sin \theta 2$. So, $\sin \theta 2=\frac{\mathrm{V}}{\mathrm{X}}$. Putting these values

$$
\mathrm{B}_{1}=\frac{\mathrm{KX}}{\pi}[2(\theta 2-\theta 1)-\sin 2 \theta 1+\sin 2 \theta 2] .
$$

Hence, the mathematical representation of describing function for the proposed model is given by

$$
\begin{gathered}
\mathrm{V}(\mathrm{X}, \omega)=\frac{\sqrt{\mathrm{A}_{1}^{2}+\mathrm{B}_{1}^{2}}}{\mathrm{X}} \angle \tan ^{-1} \frac{\mathrm{A}_{1}}{\mathrm{~B}_{1}} \\
=\frac{\mathrm{B}_{1}}{\mathrm{X}} \angle 0 . \\
\mathrm{V}(\mathrm{X}, \omega)=\frac{\mathrm{K}}{\pi}[2(\theta 2-\theta 1)-\sin 2 \theta 1-\sin 2 \theta 2] \text { for } \mathrm{X}>V \\
=1-\frac{2}{\pi}[2(\theta 2-\theta 1)-\sin 2 \theta 1+\sin 2 \theta 2] \text { for } \mathrm{V}>\mathrm{X}>\frac{\mathrm{M}}{2} .
\end{gathered}
$$

Equation (48) represents the proposed model equation considering all kinds of nonlinearity.

\section{Simulation Result}

The proposed non-linear Hamiltonian approached model has been simulated keeping mass and amplitude fix along with linear spring constant and varying the value of non-linear spring constant values and the periodic functions $\mathrm{x} 1(\mathrm{t})$ and $\mathrm{x} 2(\mathrm{t})$ are plotted concerning time. Here, mass $\mathrm{M}=1$ and $\mathrm{k} 1=5$ and $\mathrm{k} 2=3$ and $\mathrm{B}=10$ are kept constant. Figure 5 represents the simulation with $\mathrm{k}_{1}{ }^{\mathrm{N}}=1$ and $\mathrm{k}_{2} \mathrm{~N}=5$ where Figure 6 represents the simulation with $\mathrm{k}_{1}{ }^{\mathrm{N}}=3$ and $\mathrm{k}_{2}{ }^{\mathrm{N}}=7$.

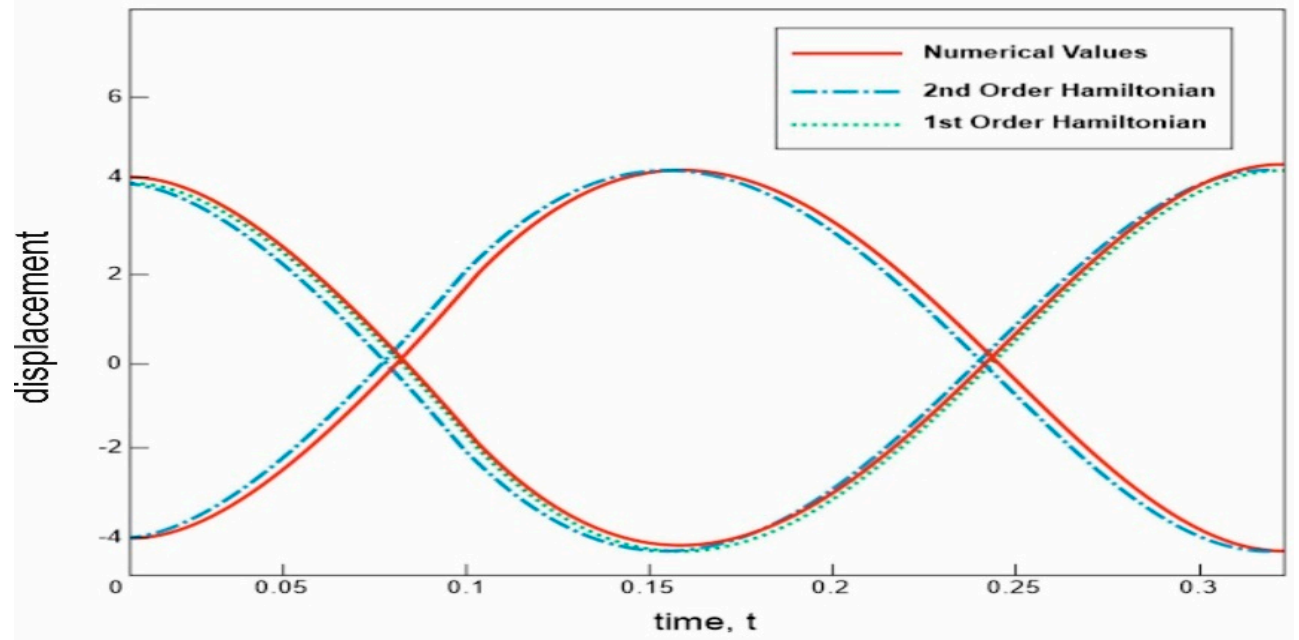

Figure 5. Plot of $x 1(t)$ and $x 2(t)$ when $k_{1}{ }^{N}=1, k_{2}{ }^{N}=5$. 


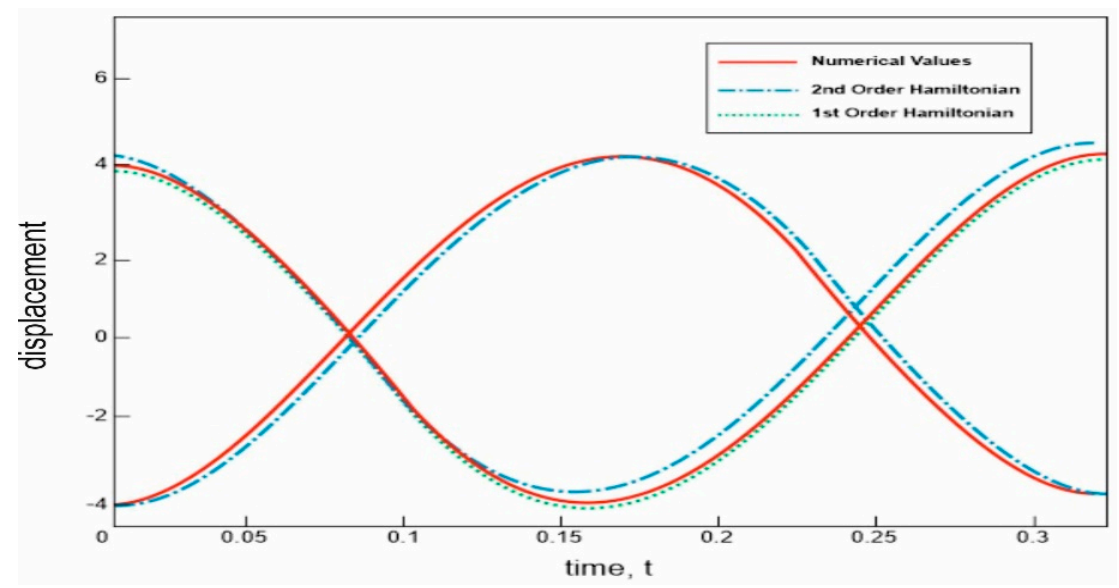

Figure 6. Plot of $x 1(t)$ and $x 2(t)$ when $k_{1}{ }^{N}=3, k_{2}{ }^{N}=7$.

Table 3 represents the parameters taken for simulation, and the corresponding values for every parameter have also been included in it.

Table 3. Value of the parameters taken for simulation.

\begin{tabular}{cc}
\hline Parameter & Values \\
\hline $\mathrm{k}_{1}{ }^{\mathrm{N}}$ & 1,3 \\
\hline $\mathrm{k}_{2}{ }^{\mathrm{N}}$ & 5,7 \\
\hline $\mathrm{M}$ & 1 \\
\hline $\mathrm{B}$ & 10 \\
\hline
\end{tabular}

Here, in the simulation, three different lines are used. Those are solid, dot, and dashed. The solid line represents the numerical values, whereas the other lines represent the first order and second-order Hamiltonian, respectively. It has been observed that the first-order and second-order Hamiltonian overlaps with numerical solutions. At time $0.05 \mu \mathrm{s}$, the numerical solution is 3.7, whereas at the same time, the simulated value of first-order and second-order Hamiltonian modeling-based simulated results are 3.69 and 3.73, respectively, which are very close to accurate or mathematical work.

Similarly, at the time $0.15 \mu \mathrm{s}$, the numerical solution is -7 , whereas at the same moment, the simulated value of first-order and second-order modeling based simulated results are -6.68 and -7.01 , respectively. The previous section has already discussed that by varying the parameter, the system amplitude, means the amplitude of the modified symmetric oscillator equation-based non-linear model, can be controlled. By running the simulation, the results are shown below. Figure 7a represents a two-dimensional (2D) phase portrait of the proposed design considering all different initial conditions, whereas Figure $7 \mathrm{~b}$ shows a 3D phase portrait for the proposed method. From the 2D phase portrait, it is evident that whatever may be the initial condition; ultimately, all state points are converging towards the equilibrium points. Hence the non-linear proposed design is stable. From the 3D phase, portrait stability can also be explained in a more prominent way than a 2D portrait. In Figure 7b, it has been observed that the initial condition may start from three independent different coordinates-based points. Still, all topics are converging towards the center of the figure, which assures stability.

From the above phase portrait, it is found that every point in the phase portrait is bounded for time, which means that the system is always converging to its equilibrium states considering any initial conditions. Hence the system is stable considering all types of nonlinearities. It is observed from the above phase portrait that, at time $25 \mu \mathrm{s}$, the phase's value is positive, but after $1 \mu \mathrm{s}$ again, the step is positive, which means that the degree may vary for time. Still, ultimately, it does not go into the negative region. 


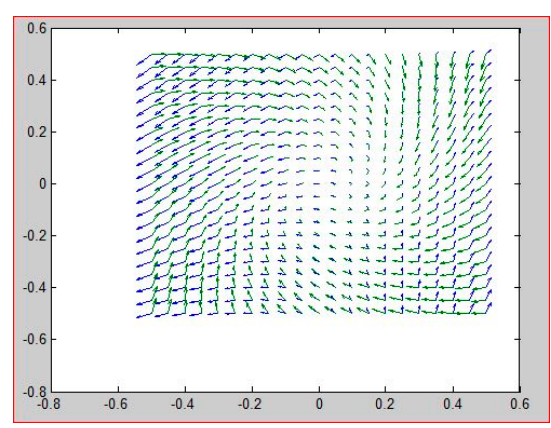

(a)

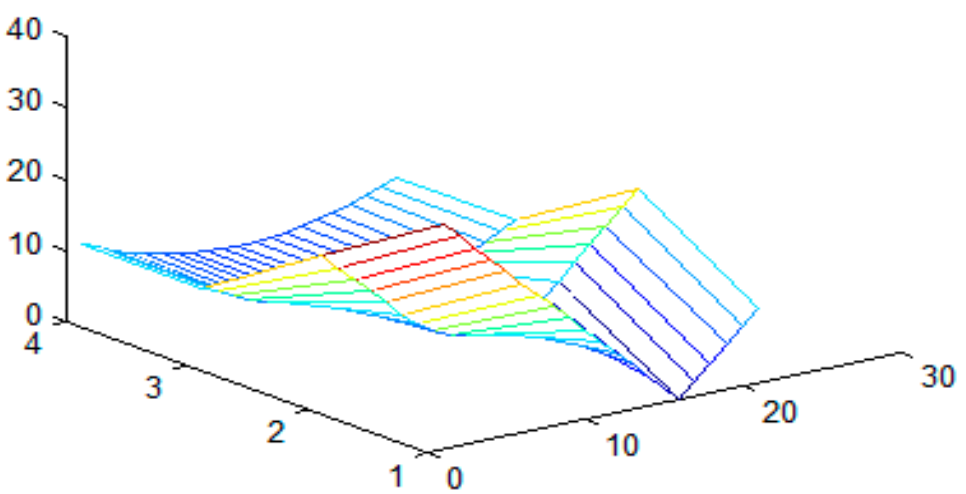

(b)

Figure 7. (a) Represents a 2D phase portrait considering the different initial conditions. (b) Represents a 3D phase portrait considering the different initial conditions.

In the above figure, the $x$-axis represents states while the $y$-axis represents the responses. Initially, we considered the value of $\sigma$ equal to unity, which is one of the van der Pol equation's essential parameters. Here, the variation has also been considered and simulated. It is found that the interpretation does not affect our system stability. Instead, Figure 8 shows that the equilibrium state point or only state points came closer to the saddle point, ensuring the design reliability. The polar plot of cardiovascular muscle is depicted in Figure 9 that will be essential to find stability in the traditional describing function method.

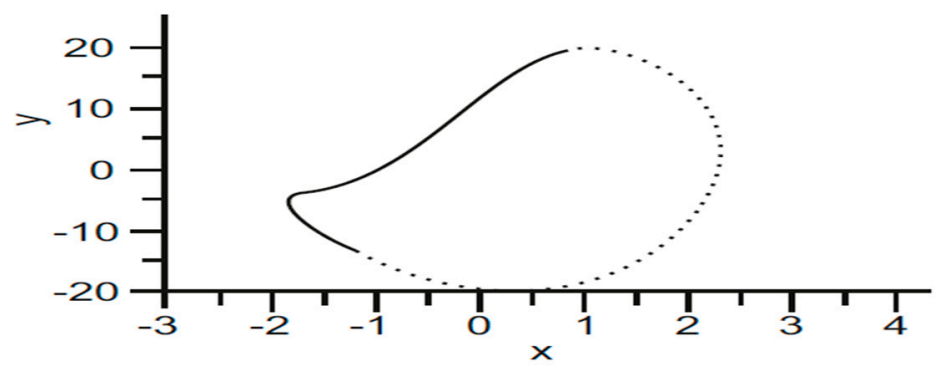

Figure 8. State point came closer to saddle point.

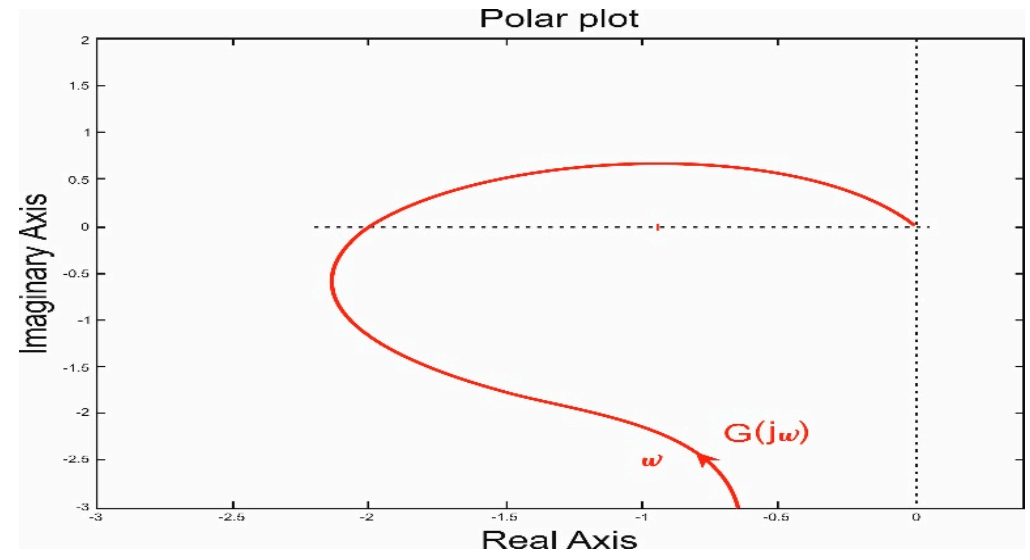

Figure 9. Polar plot of cardiac muscle.

Equation (48), representing the cardiovascular muscle model's nonlinearity, has been simulated along with a polar story shown below in Figure 10. Here, the describing function has been plotted from Equation (48) in blue color. 


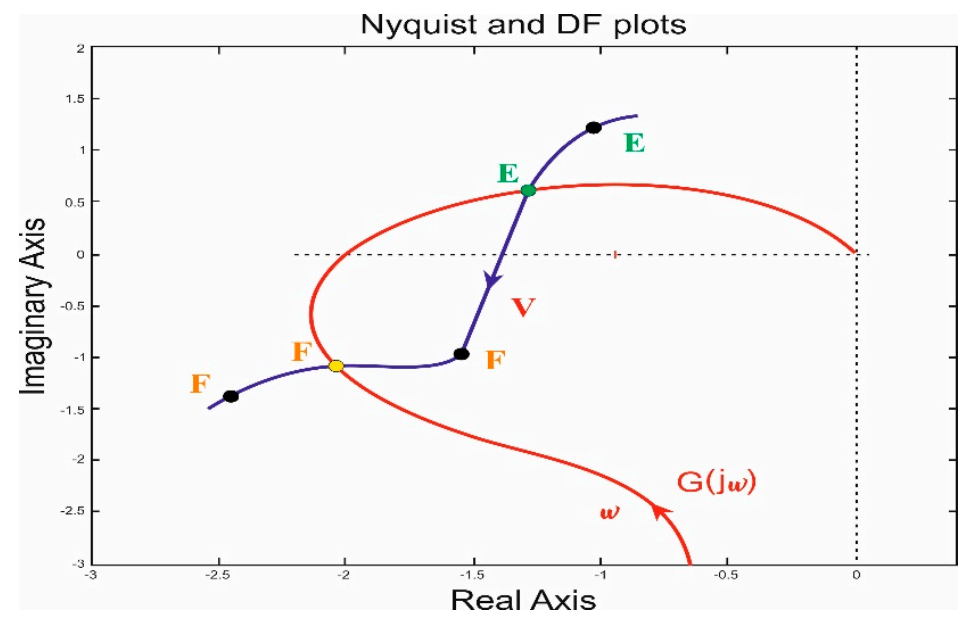

Figure 10. Superimpose of polar plot and describing function.

In the above diagram, the polar plot of the ordinary cardiovascular muscle system and its describing function characteristics has been depicted at a time. It is observed from the simulation result that an expected limit cycle is found along the path "V" for our proposed design. Moving points $\mathrm{E}$ and F represents the intersection points of the polar plot and describing functions. A completely converging limit cycle has been observed within this limit. If the points $\mathrm{E}$ and $\mathrm{F}$ move away from the polar plot, the system would be unstable. Thus, the design can work for real-life situations for a particular bounded region.

\section{Comparative Study of Our Proposed Design with Traditional Describing Function and Future Scope}

In the conventional describing function technique, a non-linear system can easily be analyzed. The nonlinearity present in cardiovascular muscle dynamics has been studied in this work in Section 10. However, the parameter responsible for nonlinearity could not be varied. In the Hamiltonian approach of nonlinearity, the parameter accountable for nonlinearity has been changed. It is observed that the variation of the spring constant does not affect our modeling. As both approaches are based on energy, the result in terms of stability remains the same. Interpretation of the non-linear parameter and strength using the Hamiltonian process is the main advantage of our proposed design over the traditional describing function method. A comparative study-based approach for human cardiovascular disease detection can be modeled in the future, considering our proposed plan as nonlinearity change parameters from person to person. Different values of the non-linear parameter can be found in various diseases, which will help future research work.

\section{Conclusions}

The human cardiovascular system's conduction process has been discussed in this work with the aid of a modified symmetric oscillator equation and an extended Hamiltonian approach for solving the motion of a non-linear system with two degrees of freedom (two degrees of freedom). The second-order approximation is observed from the simulation that the second-order Hamiltonian is overlapped with the numerical result. In our proposed model, a modified van der Pol symmetric oscillator equation has also been used to implement the series connection of two same type conduction cells of the cardiovascular system, which helps describe the complete process of conduction. The modeling can be done using only the describing function, but if the spring constant has to be varied, then the overall model equation has to be modified, which is a tedious job. Analysis of two identical cells using the Hamiltonian dynamical approach is better than describing the function approach. Using the Hamiltonian mechanics, the spring constant can easily be varied. The symmetric oscillator's natural frequency has been evaluated for the above-designed 
model compared with the previous simulated result, which shows that saddle point or breakaway point came closer with state points. This work's main advantage or beauty allows us to anticipate the human cardiovascular conduction process's properties obtained from different patients. We observed the non-linear parameter variation, which cannot be obtained from the describing function method.

Author Contributions: S.B. (Soumyendu Bhattacharjee): Conceptualization, methodology, software, validation, investigation, formal analysis, visualization, resources, data curation, writing-original draft preparation, writing — review and editing, supervision, A.B.: Project administration, software, supervision, data curation, A.R.: Formal analysis, S.B. (Swapan Bhattacharyya): writing-Review and editing, S.C.: Methodology B.S.: Conceptualization, methodology, software, validation, investigation, project administration, funding acquisition B.N.: Methodology, software, validation, project administration, funding acquisition. All authors have read and agreed to the published version of the manuscript.

Funding: This research received no external funding.

Institutional Review Board Statement: Not applicable.

Informed Consent Statement: Not applicable.

Data Availability Statement: Not applicable.

Conflicts of Interest: The authors declare no conflict of interest.

\section{References}

1. Islam, M.R.; Zulkarnain, M.I. Effect of pump characteristic (HQ) curves on the efficiency of Total Artificial Heart. In Proceedings of the 2015 International Conference on Advances in Electrical Engineering (ICAEE), Dhaka, Bangladesh, 17-19 December 2015; pp. 55-58.

2. Frazier, O. First use of an untethered, vented electric left ventricular assist device for long-term support. Circulation 1994, 89, 2908-2914. [CrossRef]

3. Ghosal, S.; Darbar, R.; Neogi, B.; Das, A.; Tibarewala, D.N. Application of swarm intelligence computation techniques in PID controller tuning: A review. In Proceedings of the International Conference on Information Systems Design and Intelligent Applications 2012 (INDIA 2012), Visakhapatnam, India, 5-7 January 2012; pp. 195-208.

4. Choi, S.W.; Min, B.G. Ventricular Assist Device Cannula and Ventricular Assist Device Including the Same. U.S. Patent 8,771,165, 8 July 2014.

5. Sarkar, B. Mathematical and analytical approach for the management of defective items in a multi-stage production system. J. Clean. Prod. 2019, 218, 896-918. [CrossRef]

6. Tayyab, M.; Jemai, J.; Han, L.; Sarkar, B. A sustainable development framework for a cleaner multi-item multi-stage textile production system with a process improvement initiative. J. Clean. Prod. 2020, 246, 119055. [CrossRef]

7. Dey, B.K.; Pareek, S.; Tayyab, M.; Sarkar, B. Autonomation policy to control work-in-process inventory in a smart production system. Int. J. Prod. Res. 2020, in press. [CrossRef]

8. Zhao, C.J.; Sun, Y.X.; Zhu, H.Q.; Liu, X.X. Axial suspension fuzzy pid control for axial artificial heart pump. Appl. Mech. Mater. 2015, 703, 323-326. [CrossRef]

9. Castro, V.J.F.; Malathi, R. Design of advanced control strategies for cardiovascular system. Mater. Today Proc. 2018, 5, 1960-1966. [CrossRef]

10. Sarkar, B.; Sana, S.S.; Chaudhuri, K.S. An imperfect production process for time-varying demand with inflation and time value of money-An EMQ model. Expert Syst. Appl. 2011, 38, 13543-13548. [CrossRef]

11. Sarkar, B. An inventory model with reliability in an imperfect production process. Appl. Math. Comput. 2012, $218,4881-4891$. [CrossRef]

12. Sarkar, B. An EOQ model with delay in payments and stock dependent demand in the presence of imperfect production. Appl. Math. Comput. 2012, 218, 8295-8308. [CrossRef]

13. Pakar, I.; Bayat, M. Analytical study on the non-linear vibration of Euler-Bernoulli beams. J. Vibroeng. 2012, 14, $216-224$.

14. Pakar, I.; Bayat, M.; Bayat, M. On the Approximate Analytical solution for parametrically excited nonlinear oscillators. J. Vibroeng. 2012, 14, 423-429.

15. Bazzani, A.; Giovannozzi, M.; Servizi, G.; Todesco, E.; Turchetti, G. Resonant normal forms, interpolating Hamiltonians and stability of area preserving maps. Physica D 1993, 64, 66-93. [CrossRef]

16. Vesely, V.; Korosi, L. Robust PID Controller Design for Nonlinear Systems; De Gruyter: Berlin, Germany, 2018 ; pp. 65-71.

17. Van der Pol, B.; van der Mark, J. The heartbeat considered as a relaxation oscillation and an electrical model of the heart. Philos. Mag. 1928, 6, 763-775. [CrossRef]

18. Boro, B. Review of Stability Analysis of Non-Linear Control Systems. IJERG 2016, 4, 193-199. 
19. Yamada, H.; Yamaguchi, M.; Kobayashi, K.; Matsuura, Y.; Takano, H. Development and test of a linear motor-driven total artificial heart. IEEE Eng. Med. Biol. Mag. 1995, 14, 84-90. [CrossRef]

20. Love, H.C.; Timms, D.L.; Nestler, F.; Frazier, O.H.; Cohn, W.E. A mock circulatory loop for designing and evaluating total artificial hearts. In Proceedings of the 2014 36th Annual International Conference of the IEEE Engineering in Medicine and Biology Society (EMBC), Chicago, IL, USA, 26-30 August 2014; pp. 5667-5670.

21. Kurita, N.; Ishikawa, T.; Saito, N.; Masuzawa, T.; Timms, D. A double-sided stator type axial self-bearing motor development for total artificial heart. In Proceedings of the 2017 IEEE International Electric Machines and Drives Conference (IEMDC), Miami, FL, USA, 21-24 May 2017; pp. 1-6.

22. Konieczny, G.; Opilski, Z.; Pustelny, T.; Gacek, A.; Gibinski, P.; Kustosz, R. Results of experiments with fiber pressure sensor applied in the polish artificial heart prosthesis. Acta Phys. Pol. Ser. A Gen. Phys. 2010, 118, 1183. [CrossRef]

23. Baldoni, J.A.; Yellen, B.B. Magnetic tracking system: Monitoring heart valve prostheses. IEEE Trans. Magn. 2007, 43, 2430-2432. [CrossRef]

24. Rosli, R.S.B.; Olanrewaju, R.F. Mobile Heart Rate Detection System (MoHeRDS) for Early Warning of Potentially-Fatal Heart Diseases. In Proceedings of the 2016 International Conference on Computer and Communication Engineering (ICCCE), Kuala Lumpur, Malaysia, 26-27 July 2016; pp. 422-427.

25. Marom, G.; Chiu, W.C.; Slepian, M.J.; Bluestein, D. Numerical model of total artificial heart hemodynamics and the effect of its size on stress accumulation. In Proceedings of the 2014 36th Annual International Conference of the IEEE Engineering in Medicine and Biology Society (EMBC), Chicago, IL, USA, 26-30 August 2014; pp. 5651-5654.

26. Shi, W.; Chew, M.S. Mathematical and physical models of a total artificial heart. In Proceedings of the IEEE International Conference on Control and Automation, Christchurch, New Zealand, 9-11 December 2009; pp. 637-642.

27. Pohlmann, A.; Leßmann, M.; Hameyer, K. Comparative study on optimization methods for a motor-drive of artificial hearts. In Proceedings of the 2010 International Conference on Electrical Machines and Systems (ICEMS), Incheon, Korea, 10-13 October 2010; pp. 1754-1758.

28. Das, S.; Nandi, D.; Neogi, B.; Sarkar, B. Nonlinear system stability and behavioral analysis for effective implementation of artificial lower limb. Symmetry 2020, 12, 1727. [CrossRef]

29. Pakar, I.; Bayat, M. Nonlinear free vibration analysis of tapered beams by Hamiltonian approach. J. Vibroeng. 2011, 13, 654-661.

30. Bayat, M.; Pakar, I. Nonlinear dynamics of two degree of freedom systems with linear and nonlinear stiffnesses. Earthq. Eng. Eng. Vib. 2013, 12, 411-420. [CrossRef]

31. Holden, A.V.; Biktashev, V.N. Computational biology of propagation in excitable media models of cardiac tissue. Chaos Solitons Fractals 2002, 13, 1643-1658. [CrossRef]

32. Bazzani, A.; Mazzanti, P.; Servizi, G.; Turchetti, G. Normal forms for hamiltonian maps and non linear effects in a particle accelerator. IL Nuovo Cim. B 1988, 102, 51-80. [CrossRef]

33. Katholi, C.R.; Urthaler, F.; Macy, J., Jr.; James, T.N. Mathematical model of automaticity in the sinus node and AV junction based on weakly coupled relaxation symmetric oscillators. Comput. Biomed. Res. 1977, 10, 529-543. [CrossRef]

34. Di Bernardo, D.; Signorini, M.G.; Cerutti, S. A model of two nonlinear coupled symmetric oscillator s for the study of heartbeat dynamics. Int. J. Bifurc. Chaos Appl. Sci. Eng. 1998, 8, 1975-1985. [CrossRef]

35. Nollo, G.; Del Greco, M.; Ravelli, F.; Disertori, M. Evidence of low and high-frequency oscillations in human AV interval variability: Evaluation with spectral analysis. Am. J. Physiol. 1994, 267, H1410-H1418. [CrossRef]

36. Zhang, H.; Holden, A.V.; Kodama, I.; Honjo, H.; Lei, M.; Varghese, T.; Boyett, M.R. Mathematical models of action potentials in the periphery and center of the rabbit sinoatrial node. Am. J. Physiol. Heart Circ. Physiol. 2000, 279, H397-H421. [CrossRef]

37. Saha, S.; Chatterjee, D.; Sarkar, B. The ramification of dynamic investment on the promotion and preservation technology for inventory management through a modified flower pollination algorithm. J. Retail. Con. Ser. 2021, 58, 102326. [CrossRef]

38. Honerkamp, J. The heart as a system of coupled nonlinear symmetric oscillators. J. Math. Biol. 1983, 18, 69-88. [CrossRef]

39. Żebrowski, J.J.; Baranowski, R. Type I intermittency in nonstationary systems-Models and human heart rate variability. Phys. A 2014, 336, 74-83. [CrossRef]

40. Keener, J.; Sneyd, J. Mathematical Physiology, Interdisciplinary Applied Mathematics 8; Springer: New York, NY, USA, 1998.

41. West, J.; Goldberger, A.L.; Rovner, G.; Bhargava, V. Nonlinear dynamics of the heartbeat. The AV junction: Passive conduit or active symmetric oscillator? Physica D 1985, 17, 198-206. [CrossRef]

42. Jemai, J.; Sarkar, B. Optimum design of a transportation scheme for healthcare supply chain management: The effect of energy consumption. Energies 2019, 12, 2789. [CrossRef]

43. Grudziński, K.; Żebrowski, J.J. Modeling cardiac pacemakers with relaxation symmetric oscillators. Phys. A 2004, 336, 153-162. [CrossRef]

44. Hodgkin, L.; Huxley, A.F. A quantitative description of membrane current and its applications to conduction and excitation in nerve. J. Physiol. Lond. 1952, 117, 500-544. [CrossRef]

45. Postnov, D.; Seung, K.H.; Hyungtae, K. Synchronization of diffusively coupled symmetric oscillator s near the homoclinic bifurcation. Phys. Rev. E 1999, 60, 2799-2807. [CrossRef]

46. Meirovitch, L. Principles, and Techniques of Vibrations; Prentice-Hall: Upper Saddle River, NJ, USA, 1997.

47. Joyner, R.W.; van Capelle, F.J.L. Propagation through electrically coupled cells: How a small SA node drives a large atrium. Biophys. J. 1986, 50, 1157-1164. [CrossRef] 
48. Jadlovska, A.; Hrubina, K.; Majercak, J. Application of Stability Theory of NonLinear Systems and Lyapnov Transformation in Control of Artificial Pneumatic Muscle. Ann. Fac. Eng. 2011, 3, 97-102.

49. Barbosa, J.R.S.; Machado, J.A.T. Describing Function Analysis of Systems with Impacts and Backlash. Nonlinear Dyn. 2002, 29, 235-250. [CrossRef]

50. Davison, E.J.; Kurak, E.M. A computational method for determining quadratic Lyapunov functions for non Linear system. Automatica 1971, 7, 627-636. [CrossRef] 